\title{
Cataract surgery alone cannot be considered an IOP-lowering procedure for open-angle glaucoma patients: an evidence-based perspective
}

\author{
Cirurgia de catarata isolada não pode ser considerada um procedimento antiglaucomatoso \\ para pacientes com glaucoma de ângulo aberto: uma perspectiva baseada em evidências
}

Tiago Santos Prata ${ }^{1,2,3}$, Michele Ushida ${ }^{1,2}$, Syril Dorairaj 4

\begin{abstract}
Due to the significant coexistence of cataract and glaucoma, cataract surgery has become a routine procedure in a glaucoma surgeon's practice ${ }^{(1-4)}$. The indication of cataract surgery in glaucoma patients usually differs from that in ordinary cases, either because of the intraoperative technique and perioperative care or because of the expected results. The approach also varies significantly among patients with glaucoma, depending on various factors such as disease stage, preoperative intraocular pressure (IOP), number of medications, gonioscopy appearance, patient's age, previous ocular surgery, comorbidities, and others. Therefore, it is essential that every surgeon recognizes the influence of cataract surgery on IOP control in each type of glaucoma, aiming, above all, to mitigate the risk of losing control of the disease.

The relationship between glaucoma and cataract surgery has been investigated in several glaucoma stu$\operatorname{dies}^{(1-3)}$. More recently, the topic began to be approached by cataract specialists in original articles, editorials, and meetings $s^{(5-7)}$. In this context, much has been discussed about the hypotensive effect of cataract surgery in patients with glaucoma or ocular hypertension. On analyzing the literature carefully, we found that most of the articles that evaluated the effects of phacoemulsification with intraocular lens implantation in patients with glaucoma included eyes with angle-closure glaucoma (either the chronic or acute form of the disease) ${ }^{(8-11)}$. Although little has been studied about the hypotensive effect of cataract surgery in eyes with open-angle glaucoma until now, the consistently good results reported on average in cases of angle-closure led to the idea that cataract surgery would be an effective IOP-lowering procedure for all cases of glaucoma ${ }^{(9,11)}$. In our opinion, this assumption seems dangerous, and to date, has no strong basis in the literature.

When focusing on previous articles that include patients with open-angle glaucoma, we come across scant data and few good studies. Most of the available studies are based on non-comparative case series with retrospective analysis. In general, a modest IOP reduction was observed after uncomplicated phacoemulsification in these patients. Among the more rigorous studies, the mean long-term changes in IOP values varied between 1.5 and $2 \mathrm{mmHg}^{(11-13)}$. For example, in a recent study by Slabaugh et al. ${ }^{(12)}$, over 150 patients with open-angle glaucoma controlled with medication underwent cataract surgery. After one year of follow-up, IOP was reduced by an average of $1.8 \pm 3.1 \mathrm{mmHg}$. Although significant from a statistical point of view, it is questionable whether this percentage reduction in IOP is clinically meaningful. When compared with the preoperative period, there was no significant change in the number of medications after cataract surgery. In this study, perhaps the most alarming report was the fact that almost $40 \%$ of these glaucoma patients lost IOP control during the first year after cataract surgery either because they needed more medication (or laser) or because of an IOP increase (in cases where there was no change in medication regimen). Very similar results had previously been demonstrated by Shingleton et al..$^{(13)}$ in a study with fewer patients but with longer follow-up time (average of 5 years). Finally, we must also highlight the effects of cataract surgery on IOP in the first few days after surgery. Patients with glaucoma, even when stabilized on topical medications, are more likely to experience IOP spikes (defined as IOP >30 mmHg) immediately after uncomplicated cataract surgery than controls; this increase being sustained during the first three days ${ }^{(14,15)}$.

In relation to other published articles, we believe that it is difficult to extract good guidelines for cases of coexisting cataract and open-angle glaucoma. In two relatively recent articles, Walland et al. ${ }^{(16,17)}$ emphasized the lack of randomized controlled trials providing adequate evidence regarding the benefit of cataract surgery in these cases. This fact, although significant, is not the most serious issue, in our opinion. For instance, some of the studies that included patients with open-angle glaucoma did not even use gonioscopy as an inclusion (or exclusion) criteria ${ }^{(6,7)}$. Finally, two important points should be highlighted. First, there appears to be a clear positive
\end{abstract}

Submitted for publication: July 11, 2015

Accepted for publication: July 30, 2015

${ }^{1}$ Department of Ophthalmology, Glaucoma Service, Universidade Federal de São Paulo (UNIFESP), São Paulo, SP, Brazil.

2 Glaucoma Unit, Hospital Medicina dos Olhos (HMO), Osasco, SP, Brazil.

${ }^{3}$ Department of Ophthalmology, Glaucoma Service, Hospital Oftalmológico de Sorocaba (BOS),

Sorocaba, SP, Brazil.

${ }^{4}$ Department of Ophthalmology, Glaucoma Service, Mayo Clinic, Jacksonville, Florida.
Funding: No specific financial support was available for this study.

Disclosure of potential conflicts of interest: None of the authors have any potential conflicts of interest to disclose.

Corresponding author: Tiago Prata. Rua Dr. José Rodrigues Alves Sobrinho, 125 - São Paulo, SP 05466-040 - Brazil - E-mail: tiagoprata@ig.com.br 
bias towards the indication of cataract surgery in these cases and a considerable amount of speculation (based on personal opinions, without scientific basis) in the conclusions of some authors ${ }^{(5)}$. Second, the type of statistical analysis used in some studies is at least questionable, with stratification of patients into distinct groups based on preoperative $\mathrm{IOP}^{(6,7)}$. Looking at the mean preoperative and postoperative IOP values of the entire group of patients (as a whole), one can note that the average IOP reduction is modest, at most, in cases of open-angle glaucoma ${ }^{(18)}$. However, when the patients are stratified into groups according to their preoperative IOP, the results appear to change (favoring a better outcome in eyes with higher baseline IOP). Because the preoperative and postoperative IOP comparisons are not based on averages derived from several IOP measurements but from a few isolated IOP measurements taken during the follow-up, this type of stratified analysis can lead to a greater (artificial) IOP reduction in those eyes with very high preoperative IOP values due to regression to the mean ${ }^{(18-20)}$.

We believe that much of the hypotensive effect arising from lens extraction is related to the anatomical configuration of the anterior chamber and the degree of angle opening, in addition to the functional reserve of the trabecular meshwork. In this context, eyes with shallower chambers, greater influence of the lens component (greater lens vaults), narrower angles without extensive synechiae, and good trabecular function could most benefit from cataract surgery in terms of IOP reduction ${ }^{(21,22)}$. This seems to explain the modest effect of phacoemulsification in controlling IOP in eyes with open-angle glaucoma. In fact, a recent report from the American Academy of Ophthalmology supports such considerations. After reviewing over 500 citations (less than 10\% met the panel criteria), the authors found that although phacoemulsification reduced IOP by $30 \%$ and glaucoma medications by $58 \%$ in patients with angle-closure glaucoma, it resulted in significantly smaller reductions of IOP and medications for patients with open-angle glaucoma (13\% and $12 \%$, respectively $)^{(11)}$. Hence, while some authors have been defending phacoemulsification surgery as an effective way of controlling IOP in eyes with glaucoma, this seems to be valid only for those with angle-closure glaucoma. At the present time, we have not found good quality evidence in the literature to suggest phacoemulsification as an IOP-lowering procedure in patients with open-angle glaucoma. We also reinforce that, in all cases of coexisting glaucoma and cataract, factors, such as the number of drugs, disease stage, and level of IOP, should be assessed individually and carefully to determine whether or not combined surgery is required at the time of cataract extraction ${ }^{(8,23)}$.

\section{REFERENCES}

1. Musch DC, Gillespie BW, Niziol LM, Janz NK, Wren PA, Rockwood EJ, et al. Collaborative Initial Glaucoma Treatment Study Group. Cataract extraction in the collaborative initial glaucoma treatment study: incidence, risk factors, and the effect of cataract progression and extraction on clinical and quality-of-life outcomes. Arch Ophthalmol. 2006;124(12):1694-700.

2. The advanced glaucoma intervention study, 6 : effect of cataract on visual field and visual acuity. The AGIS Investigators. Arch Ophthalmol. 2000;118(12):1639-52.

3. Comparison of glaucomatous progression between untreated patients with normaltension glaucoma and patients with therapeutically reduced intraocular pressures. Collaborative Normal-Tension Glaucoma Study Group. Am J Ophthalmol. 1998;126(4): 487-97.

4. Quigley HA, Cassard SD, Gower EW, Ramulu PY, Jampel HD, Friedman DS. The cost of glaucoma care provided to Medicare beneficiaries from 2002 to 2009. Ophthalmology. 2013;120(11):2249-57.

5. Brown RH, Zhong L, Lynch MG. Lens-based glaucoma surgery: using cataract surgery to reduce intraocular pressure. J Cataract Refract Surg. 2014;40(8):1255-62.

6. Poley BJ, Lindstrom RL, Samuelson TW. Long-term effects of phacoemulsification with intraocular lens implantation in normotensive and ocular hypertensive eyes. J Cataract Refract Surg. 2008;34(5):735-42.

7. Poley BJ, Lindstrom RL, Samuelson TW, Schulze R Jr. Intraocular pressure reduction after phacoemulsification with intraocular lens implantation in glaucomatous and nonglaucomatous eyes: evaluation of a causal relationship between the natural lens and open-angle glaucoma. J Cataract Refract Surg. 2009;35(11):1946-55.

8. Tham CC, Leung DY, Kwong YY, Liang Y, Peng AY, Li FC, Lai JS, Lam DS. Factors Correlating With Failure to Control Intraocular Pressure in Primary Angle-Closure Glaucoma Eyes With Coexisting Cataract Treated by Phacoemulsification or Combined Phacotrabeculectomy. Asia Pac J Ophthalmol (Phila). 2015;4(1):56-9.

9. Hayashi K, Hayashi H, Nakao F, Hayashi F. Effect of cataract surgery on intraocular pressure control in glaucoma patients. J Cataract Refract Surg. 2001;27(11):1779-86.

10. Euswas A, Warrasak S. Intraocular pressure control following phacoemulsification in patients with chronic angle closure glaucoma. J Med Assoc Thai. 2005;88 Suppl 9:S121-5.

11. Chen PP, Lin SC, Junk AK, Radhakrishnan S, Singh K, Chen TC. The Effect of Phacoe- mulsification on Intraocular Pressure in Glaucoma Patients: A Report by the American Academy of Ophthalmology. Ophthalmology. 2015. In press.

12. Slabaugh MA, Bojikian KD, Moore DB, Chen PP. The effect of phacoemulsification on intraocular pressure in medically controlled open-angle glaucoma patients. Am J Ophthalmol. 2014;157(1):26-31.

13. Shingleton BJ, Pasternack JJ, Hung JW, O'Donoghue MW. Three and five year changes in intraocular pressures after clear corneal phacoemulsification in open angle glaucoma patients, glaucoma suspects, and normal patients. J Glaucoma. 2006;15(6):494-8.

14. Yasutani H, Hayashi K, Hayashi H, Hayashi F. Intraocular pressure rise after phacoemulsification surgery in glaucoma patients. J Cataract Refract Surg. 2004;30(6):1219-24.

15. Legrand M, Blumen-Ohana E, Laplace O, Adam R, Akesbi J, Colas E, et al. Early postoperative intraocular pressure after phacoemulsification: Normal patients versus glaucoma patients. J Fr Ophtalmol. 2015. In press.

16. Walland MJ, Thomas R. Lens surgery to treat open-angle glaucoma: triumph of hope over (evidence-based) experience. J Cataract Refract Surg. 2015;41(1):247-8.

17. Walland MJ, Parikh RS, Thomas R. There is insufficient evidence to recommend lens extraction as a treatment for primary open-angle glaucoma: an evidence-based perspective. Clin Experiment Ophthalmol. 2012;40(4):400-7.

18. Slabaugh MA, Chen PP. The effect of cataract extraction on intraocular pressure. Curr Opin Ophthalmol. 2014;25(2):122-6.

19. Shrivastava A, Singh K. The effect of cataract extraction on intraocular pressure. Curr Opin Ophthalmol. 2010;21(2):118-22.

20. Parrish RK $2^{\text {nd }}$. The European Glaucoma Prevention Study and the Ocular Hypertension Treatment Study: why do two studies have different results? Curr Opin Ophthalmol. 2006;17(2):138-41.

21. Huang G, Gonzalez E, Lee R, Chen YC, He M, Lin SC. Association of biometric factors with anterior chamber angle widening and intraocular pressure reduction after uneventful phacoemulsification for cataract. J Cataract Refract Surg. 2012;38(1):108-16.

22. Mansouri M, Ramezani F, Moghimi S, Tabatabaie A, Abdi F, He M, et al. Anterior segment optical coherence tomography parameters in phacomorphic angle closure and mature cataracts. Invest Ophthalmol Vis Sci. 2014;55(11):7403-9.

23. Dietlein TS, Jordan J, Dinslage S, Lüke C, Krieglstein GK. [Early postoperative spikes of the intraocular pressure (IOP) following phacoemulsification in late-stage glaucoma]. Klin Monbl Augenheilkd. 2006;223(3):225-9. 